\title{
ALGUNAS OBSERVACIONES SOBRE CONFESIONALISMO Y CUESTIONES LINGÜÍSTICAS
}

José F. Durán Velasco

A menudo la valoración positiva o negativa de un idioma depende de la confesión religiosa o la ideología de las personas, no sólo cuando se trata de un idioma ajeno sino incluso cuando se trata de la lengua materna o de la variedad estandarizada más próxima a la lengua materna.

La valoración de la lengua árabe por los arabófonos varía según su ideología. que habitualmente depende de la religión que profesen o de su confesión de origen aunque no sean creyentes.

El maltés es un dialecto árabe con una fortísima aportación italiana y que se escribe con el alfabeto latino. Sin embargo, muchos malteses han negado la vinculación de su lengua con él árabe y han inventado teorías absurdas sobre el origen de su idioma que no vendría del árabe sino del púnico o, cuando menos, tendría una origen mixto púnico-árabe.

De un modo parecido, en el Líbano, muchos cristianos, especialmente maronitas, se dicen fenicios. No sólo rechazan la idea de ser árabes (aunque en el caso de los maronitas y algunos otros cristianos libaneses es posible que muchos de ellos tengan más antepasados árabes que los cristianos palestinos y que muchos musulmanes que se proclaman ardientemente árabes) sino que su hostilidad visceral a todo lo árabe les lleva al rechazo del propio idioma árabe o al menos a su versión estándar clásica que les parece demasiado relacionada con el nacionalismo árabe y el islam. Tradicionalmente los maronitas y otros cristianos siriacos (como los jacobitas y los nestorianos) han escrito el árabe en karšūnī, es decir, en alfabeto siriaco. En cambio los cristianos melkitas o bizantinos (que en la época moderna han sido los más inclinados al nacionalismo árabe) no han empleado nunca este tipo de escritura. Incluso en la India, en Kerala, los cristianos malabares (de rito sirio) han escrito en karšūnī, aunque no el árabe sino la lengua de su país, el malayalam ${ }^{1}$. No obstante en la actualidad esta escritura no parece que sea una alternativa al alfabeto árabe. Cuando el poeta libanés Sa ${ }^{\top} \mathbf{1}{ }^{c} \mathrm{Aql}$ propuso sustituir el árabe clásico por el árabe libanés y abandonar el alfabeto árabe no propuso volver a escribir en karšūnī (y menos todavía en alfabeto fenicio llevando hasta sus últimas consecuencias sus postulados fenicistas) sino cambiarlo por el alfabeto latino.

Los judíos arabófonos solían hacer un uso escrito de la lengua árabe pero no exactamente del árabe clásico sino de su árabe coloquial o de un tipo de lengua media que sin caer en el dialecto puro tampoco era la lengua clásica y, normalmente, empleaban los caracteres hebreos.

${ }^{1}$ G. Troupeau, s.v. "Karshūnī", E.I., IV, 699. 
Los caraítas eran mucho más proclives que los rabbanitas a escribir en árabe haciendo uso del alfabeto árabe, pero en ello influía no poco el afán caraíta de hacer lo contrario que los rabbanitas $^{2}$; en esta actitud de moderado desapego respecto al alfabeto hebreo quizás contribuyera también el hecho de que, lo que hoy se conoce como alfabeto hebreo, en su origen era simplemente el alfabeto arameo cuadrado y el alfabeto hebreo original (idéntico al fenicio) fuera abandonado por decisión de los rabinos que de manera autoritaria repudiaron la escritura hebrea e impusieron la aramea cuadrada (en su origen a esta escritura se le llamaba "asiria") $)^{3}$ d dado el poco aprecio que los caraítas tenían por los rabinos talmudistas autores de esa decisión, se comprende que su reverencia por esa escritura fuese menor que la de los rabbanitas. En cualquier caso los judíos caraítas eran los judíos más asimilados en el mundo árabe ${ }^{4}$.

En el habla cotidiana, existen diferencias en el habla de los cristianos y los musulmanes. A muchos cristianos cierto tipo de expresiones les suenan islámicas y las evitan, aunque en principio sean simplemente expresiones piadosas que no tendrían porqué entenderse como de una confesión determinada,como es el caso de ya 'țika-l-'äfiye, yislam yadayk o la iraquí Allāhu bi-l-jayr, y no digamos ya el saludo al-salām 'alaykum o, lo que en ciertos contextos se ha convertido en un grito de guerra musulmán, Allăhu akbar ("Dios es más grande", que los periodistas ignorantes acostumbran a traducir como "Alá es grande"). Estas expresiones, incluida la última, podrían ser perfectamente utilizadas por un cristiano, pues nada hay en ella que vaya en contra de sus creencias cristianas $y$, de hecho, no se puede ser cristiano si efectivamente no se cree que Dios es más grande que cualquiera de las cosas de la creación. Un palestino ateo de origen musulmán me decía una vez que, en realidad, por pura lógica, un cristiano estaría más cerca de un musulmán que un ateo como él, cosa que parece bastante lógica. Sin embargo, la dinámica del confesionalismo es tan fuerte que basta que estas expresiones sean muy utilizadas por los musulmanes para que los cristianos las rechacen sin pararse a pensar en su significación al margen de los prejuicios confesionalistas. Expresiones que en principio no tendrían necesariamente sentido religioso, o no tendrían que tenerlo necesariamente, son evitadas por personas secularistas; en otra ocasión, un sirio que se definía como ateo, decía que él jamás utilizaba la expresión al-salām ${ }^{c}$ alaykum porque le sonaba como demasiado islámica y añadía que aunque no sentía una especial aversión hacia el islam, en el que veía muchas cosas buenas y reconocía la belleza de ese saludo, prefería evitarlo porque lo asociaba con elementos fanáticos.

Por su parte muchos cristianos, lamentablemente, introducen en su habla árabe elementos foráneos, sobre todo franceses en Siria y el Líbano, que deforman de manera grotesca su árabe, sustituyendo hermosas expresiones árabes como șabăh al-jayr y șabăh al-nür o šukran por cursiladas a la francesa como "bonŷur", "bonŷurén" y "mersî".

${ }^{2}$ Camila Adang, Islam frente a judaísmo. La polémica de Ibn Hazm de Córdoba, Madrid, 1994, 93-94.

${ }^{3}$ Rudolf Meyer, Gramática de la lengua hebrea, Capellades (Barcelona), 1996, 54-55.

${ }^{4}$ Laurent Chabry y Annie Chabry, Politique et minorités au Proche-Orient, París, 1987, 286. 
Șafā' Fathīi, escritora y cineasta feminista egipcia, por reacción al ambiente opresivo de su país emigró a París y en principio, como ella misma dice, "rechazaba todos los elementos culturales, políticos, tradicionales, religiosos, sociales, que constituyen la sociedad egipcia. Llegué incluso a renegar de mi misma lengua; no quería hablar en árabe. Evitaba a los egipcios, no quería ver a ninguno, no daba mi teléfono a nadie", esto era así porque "Para una chica en mi situación, perteneciente a una familia muy tradicional, ligada al medio rural, con un padre dispuesto a ejercer su autoridad de manera violenta si era preciso, incluso con amenazas de muerte, la única manera de escapar parecía ser huir lo más lejos posible y renegar abiertamente de todos los componentes de mi identidad. Por ello, varios años más tarde, ya fuera de Egipto, rehuía el mínimo contacto con mis compatriotas. Mi identidad era mi prisión" y "En Egipto comprendí, de manera intuitiva, que para crecer y forjar mi personalidad, debía romper radicalmente con todo y partir. Lo necesitaba para disponer de un espacio mental propio. Lo necesitaba para disponer de un espacio mental propio. Tenía que irme a un lugar donde consiguiera estar completamente sola, donde no conociera a nadie, desligada radicalmente de mi manto anterior y eso sólo lo encontré en París". Sin embargo la cosa no era tan fácil: "Tras quince años en Francia, lo veo diferente. Hoy vuelvo a apreciar muchas cosas de mi país. Pero sigo pensando que uno debe tener una personalidad fuerte, ya constituida, para poder resistir a esa tentación permanente de dejar que se metan en tu vida para dejarte llevar", "Me sentí muy mal. En Egipto me proyectaban una imagen inferior de mí misma por ser mujer y en Francia por ser árabe". En todo caso no se atrevió a volver a Egipto hasta pasados muchos años y encontró las cosas allí "de forma más catastrófica si cabe" y comprobaba que el avance del integrismo islámico había afectado hasta al árabe que se habla en su país: "He notado también una gran diferencia en el lenguaje diario, se van sustituyendo algunas fórmulas de cortesía o saludos como "sabăh al-jeyr" ("La mañana de bondad") o el "allo" teléfonico, reemplazado por el islámico "As-salamucaleykum". Se está produciendo una uniformización verdaderamente increíble, a partir de un modelo religioso que abarca todos los aspectos, incluso los mismos detalles, de la vida cotidiana. Nunca antes había oído hablar de los cristianos como kăfir, infieles; no hace falta recordar que cristianos y judíos gozan del mayor respeto en el islam. Pues bien, ahora eso comienza a resultar normal. Y ello sucede en un lugar como al-Minyâ donde los cristianos son aproximadamente la mitad de la población"s.

En las zonas donde no se habla árabe o las poblaciones arabófonas no musulmanas son inexistentes, la palabra Allăh puede adquirir un tono específica y hasta exclusivamente islámico. Por ejemplo, en 1981 el gobierno de Malasia prohibió una Biblia traducida al malayo por misioneros cristianos porque algunos musulmanes se quejaron de que traducía Dios por Allāh, en vez de emplear la palabra malaya genérica para divinidad que es tuhan; para estos musulmanes malayos, Allăh era únicamente el dios musulmán ${ }^{6}$.

5 Jordi Esteva, Mil y una voces, Madrid, 1998, 276-281.

${ }^{6}$ Daniel Pipes, El Islam, Madrid, 1987, 40. 
Mientras que para un árabe oriental (sirio, libanés, egipcio, iraquí, palestino, etc) y para muchos orientales no árabes como los iraníes (que no usan la paralabra Allāh más que en locuciones árabes y emplean la palabra persa Jodá) Allăh es "Dios en árabe", para muchos magrebíes Allăh no es simplemente "Dios en árabe" sino "el dios de los musulmanes" de un modo parecido a como lo ven los musulmanes malayos. Hay que decir que en las propias hablas bereberes los términos para referirse a la divinidad (al contrario de lo que ocurre en persa y otras lenguas de oriente) están tomados del árabe. Al no existir comunidades arabófonas indígenas no musulmanas (con la excepción de los judíos que llevaban una vida muy marginal y que en la actualidad o han desaparecido, o se han reducido a un número insignificante o se han afrancesado), los únicos no musulmanes que conocen son los europeos (a los que se supone cristianos) que hablaban idiomas muy distintos al árabe (o al bereber islamo-arabizado). En el Mediterráneo occidental entre los cristianos y los musulmanes ha existido un abismo no sólo religioso sino lingüístico, cultural y étnico sin parangón en el Mediterráneo oriental y el Oriente Próximo. Lo confesional ha tendido a confundirse con lo extraconfesional tanto entre los magrebíes como entre los europeos porque el corte que separaba a unos y otros era total.

Muchos musulmanes decían que la lengua árabe no podía "cristianizarse", con lo que se pretendía dar por sentada la incapacidad de los cristianos para escribir con buen estilo en "la lengua del Corán".

Gadafi decía que los árabes cristianos debían convertirse al islam porque de lo contrario serían como un cuerpo árabe con un alma europea. Pero no se le ocurrió pensar que, aplicando la misma regla de tres a los musulmanes de Europa, un albanés o un bosnio musulmanes deberían hacerse cristianos ipso-facto para exorcizar cuanto antes el espectro turco que les tiene poseídos y volver a ser enteramente europeos.

En Túnez tradicionalmente a los judíos les estaba prohibido escribir en árabe clásico pero escribían el árabe dialectal en caracteres hebreos. Con la independencia, por el contrario, se les quiso obligar a convertir el árabe clásico en el idioma predominante de su educación, lo que provocaba el dilema en los padres judíos sobre el tipo de educación más conveniente para sus hijos, ya que optar por el árabe en lugar del francés les parecía una mala elección para su futuro ${ }^{8}$. Tengamos en cuenta que antes los musulmanes les prohibían utlilizar el árabe clásico porque no querían que los judíos usasen "la lengua del Corán", mientras que ahora querían imponérselo por serlo. Dicho de otro modo: Antes los judíos eran una minoría marginal a la que se trataba de mantener aparte y se trataba de que no participasen de "la lengua del islam", mientras que con las nuevas ideas nacionalistas (nacional-islamistas) se trataba de imponer a los judíos el árabe por ser la "lengua nacional" (que lo era por ser la lengua del islam), de modo que tunecino, árabe y musulmán venían a ser tres cosas casi sinónimas. La actitud seguía

${ }^{7}$ Leonor Martínez Martín, Antología de poesía árabe contemporánea, Madrid, 1972, 42.

8 Robert Attal, s.v. "Tunis, Tunisia", Encyclopedia Judaica, volumen 15, Jerusalén, 1972, 1449. 
siendo la misma: antes y ahora el árabe clásico debía su situación privilegiada a su condición de idioma de los musulmanes pero mientras que antes (con el islamismo asecas) se consideraba impropio e indeseable que los judíos lo usasen, después (con el nacional-islamismo) se les quería imponer.

En algunos países había grandes diferencias entre el árabe coloquial de los judíos y el de los musulmanes hasta el punto de que en el mismo país y aun en las mismas ciudades unos y otros hablen dialectos muy distintos. Así ocurría en el Magreb y en Iraq. En este último país las hablas de los judíos se asemejaban bastante a las de los cristianos pero eran bastante diferentes de las de los musulmanes; las hablas de los judíos, como las de los cristianos, derivaban de las hablas árabes del periodo 'abbāsí mientras que las hablas de los musulmanes era de tipo beduino. Esto era así porque los musulmanes habían sido muy influidos por los beduinos mientras que los cristianos y judíos, replegados en sus propias comunidades, habían conservado los dialectos antiguos ${ }^{9}$. El habla de los judíos iraquíes era objeto de irrisión por parte de sus compatriotas musulmanes ${ }^{10}$.

Los judíos arabófonos no se suelen considerar árabes ni suelen ser considerados árabes por los árabes musulmanes, cristianos o drusos. Y ello a pesar de que por los menos los judíos yemeníes son fundamentalmente descendientes de árabes qahtaníes convertidos al judaísmo en los siglos IV y VI ${ }^{11}$, lo que no excluye una cierta aportación de elementos judíos venidos de fuera del Yemen que habrían sido los introductores de la religión judía, pero el elemento mayoritario en el origen de los judíos yemeníes era en todo caso el de los prosélitos surarábigos; como es bien sabido, el propio rey del Yemen, D̄ū Nuwās, era uno de estos prosélitos y su persecución a los cristianos provocó la intervención que acabó con él. En todo caso el atraso del Yemen y las duras condiciones de opresión en las que vivían los judíos yemeníes contribuyeron a que su cultura fuera exclusivamente judía y emplearan el hebreo y no el árabe (o por lo menos no el árabe clásico) como lengua escrita y de cultura. El poeta Samaw ${ }^{\mathrm{c}} a l$ (Samuel) ibn ${ }^{\mathrm{c}}$ Adiya, el Guzmán el Bueno de la Arabia preislámica, era judío. Las tribus judías del Hiŷāz buscaron asilo entre sus correligionarios de Siria cuando fueron expulsadas de su país por los musulmanes, por lo que también en los judíos de Siria podría haber un componente árabe originario aunque fuera en escasa medida.

Una cosa curiosa que ha ocurrido en el mundo árabe actual es que la palabra yahūdīha pasado del desprecio tradicional (Edward Lane cuenta que en la primera mitad del siglo XIX "judío" era el insulto definitivo que los musulmanes solían dedicar a sus asnos insumisos después de haberles dicho todos los demás) ${ }^{12}$ a una especie de demonización, por no hablar

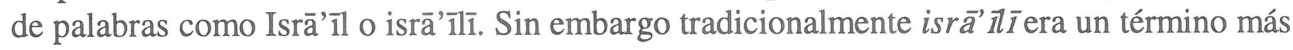

9 J. Blau, s.v. "Judéo-arabe", E.I., IV, 314-315.

${ }^{10}$ Naïm Kattan, Adieu Babylone, París, 1975.

${ }^{11}$ Laurent Chabry y Annie Chabry, Politique et minorités au Proche-Orient, París, 1987, 292.

12 Edward William Lane, Maneras y costumbres de los modernos egipcios, Madrid, 1993, 531. 
cortés para referirse a un judío que yahūdī (que podía sonar despectivo). La palabra isrā’ $\mathfrak{\imath} \overline{1}$ la empleaban comúnmente los autores musulmanes para referirse a sus colegas judíos e incluso para los judíos convertidos al islam, como Ibn Sahl al-Isrā'îlī. Esto era así porque la palabra isrẩ î̀ $\bar{y}$ tenía un sentido étnico más que religioso. Los autores tardíos distinguían a los $B a n \bar{u}$ Isrǟ $\vec{l}$ ("hijos de Israel" o israelitas) de los yahüd (judíos): los Banū Isrǟ $\vec{l}$ eran los israelitas de origen mientras que los yahüd incluían a los árabes, rūm y otros convertidos al judaísmo ${ }^{13}$. Mientras que existía un gran respeto por los israelitas, pueblo de la progenie de profetas muy respetados por el islam, la opinión que los musulmanes tenían de los judíos como religión era muy despectiva, cosa que no tiene nada de particular porque la aversión de los musulmanes tradicionales hacia los judíos era religiosa, no étnica ni racial. Con la creación del estado de Israel la palabra isrẩ î̀ se volvió tabú y la propia revista de los judíos del Líbano que hasta entonces se había llamado $a l$ - $^{c} \bar{A} l a m$ al-isrä’ $̄ \bar{l}$ ("el mundo israelita"), pasó a llamarse al-Salām ("la paz") ${ }^{14}$. En persa se usa como término más cortés para los judíos la palabra kalimí, que hace referencia a Moisés, llamado Kalīm Allāh.

Por parte judía la palabra "árabe" se convierte en algo impensable para referirse a los judíos, incluso a los judíos arabófonos, y mientras que se habla de judíos europeos para referirse a los judíos israelíes procedentes de Europa, es impensable llamar "judíos árabes" a los judíos procedentes de los países árabes y se prefieren expresiones mucho más inexactas como "judíos orientales" (no deja de ser irónico geográficamente que un judío marroquí sea una "judío oriental" mientras que un judío polaco o ruso sea un "judío occidental") o simplemente confusas (por no decir simplemente erróneas) como llamarlos sefardíes, lo que ha llevado a tener que llamar "sefardíes puros" a los auténticos sefardíes para distinguirlos de los otros.

Muchos judíos israelíes, sobre todo los provenientes de los países árabes, saben hablar árabe, pero es posible que no les guste hablarlo y que si un extranjero se dirige a ellos en árabe no les resulte demasiado simpático.

Del mismo modo, la mayoría de los árabes de Israel habla y escribe el hebreo con fluidez, ya que suelen necesitarlo para trabajar y muchos leen la prensa hebrea y ven la televisión hebrea; sin embargo en general no creo que la lengua hebrea les produzca gran alborozo. Los palestinos de los territorios ocupados (y territorios ex-ocupados) también conocen el hebreo pero tampoco es idioma por el que sientan ningún cariño y no acogen con simpatía al extranjero que se dirija a ellos en ese idioma y es posible que rehúsen hablar con él en hebreo, que para ellos es la lengua de la ocupación, la lengua del "enemigo sionista".

El estudio de un profesor marroquí sobre los šămiyyūn emigrados a "América Latina" revelaba que el idioma árabe tendía a conservarse más en la segunda y tercera generaciones entre los musulmanes, menos entre los cristianos ortodoxos y entre los que menos entre los

${ }^{13}$ S. D. Goitein, s.v, "Banū Isrā'̄il", E.I., I, 1053.

${ }^{14}$ Hayyim J. Cohen, s.v, "Beirut", Encyclopedia Judaica, volumen 4, Jerusalén, 1972, 403. 
cristianos maronitas. Estos últimos solían sentir por el árabe un particular desprecio que transmitían a sus hijos. A la inversa, los maronitas eran los más integrados en el país de inmigración y los que menos iban a su país de origen a buscar consorte; los musulmanes eran los menos integrados y los que más volvían para casarse con alguien de su país de origen y los ortodoxos ocupaban un lugar intermedio en esos aspectos entre los maronitas y los musulmanes. En su país de origen las relaciones entre maronitas y musulmanes eran francamente malas y en el Nuevo Mundo llegaron a ser todavía peores, pues pasaron de la antipatía a la abierta hostilidad ${ }^{15}$. En cambio los judíos, que en Siria habían tenido no pocos problemas y conflictos con sus compatriotas musulmanes, en la Argentina mantenían con ellos relaciones buenas de antiguos compatriotas. Esto era así porque mientras en el Mahŷar se esfumaba la antigua hostilidad antijudía, en el Mahŷar era precisamente donde los maronitas podían dar rienda suelta con más libertad a su aversión a los musulmanes sin estar obligados a contemporizar con ellos como en su país de origen. Los maronitas no suelen considerarse árabes y suelen ver con suma antipatía el panarabismo. En general es más fácil caerles simpático a los cristianos libaneses hablándoles en francés que hablándoles en árabe, y no es nada infrecuente que, si se les habla en árabe, contesten en francés y se nieguen a hablar en árabe.

La antipatía de los maronitas hacia todo lo árabe es fácilmente comprensible si se tiene en cuenta cual ha sido la actitud de los que se dicen árabes hacia ellos. A pesar de la enorme contribución de los maronitas a la cultura árabe moderna, los maronitas y otros cristianos han podido comprobar que sólo se les considera árabes cuando conviene a los intereses musulmanes pero no cuando les beneficiaría a ellos. Se les considera árabes para negarles el derecho a la autodeterminación y a tener un proyecto nacional propio e independiente, pero no se benefician en ningún momento de la solidaridad árabe.

En el caso de los judíos, el odio que existe contra ellos es tan grande que a pocos se les ocurre que, siendo coherentes con el panarabismo laico, los judíos de los países árabes serían tan árabes como sus paisanos (y ex-paisanos) de los países en los que viven o de los que son originarios. Sin embargo la mayoría considera que su repudio del arabismo los convierte en no árabes, sin tener en cuenta que, si eso es así, también el repudio del arabismo de la mayoría de los cristianos libaneses les convertiría en no árabes. La diferencia entre ambos casos radica en que el nacional-islamismo tiene como objetivo la aniquilación de Israel por la fuerza y de modo declarado, mientras que su objetivo respecto al Líbano es fagocitarlo en un marco árabe más amplio mayoritariamente musulmán y sunní, lo que implica el anatema (en el sentido bíblico) para los judíos israelíes (incluidos los originarios de los países árabes) y la negativa al "divorcio" para los cristianos maronitas.

La arabidad de los judíos originarios de los países árabes sólo se ha invocado algunas pocas veces cuando convenía reducir a los judíos a "mera confesión religiosa" para negarles

${ }^{15}$ Abdelouahed Akmir, "La inmigración árabe en Argentina", en El Mundo Árabe y América Latina, coordinada por Raymundo Kabchi, Madrid, 1987, 87-97. 
cualquier derecho nacional pero jamás en beneficio de los judíos sino buscando su daño (como en el caso de los maronitas). Jamás se les veía como connacionales a los que se había agraviado y a los que era necesario atraer a la casa común de la Nación Árabe laica de la que eran miembros de pleno derecho.

Uno de los mejores poemas de Mahmūd Darwīš sobre la guerra del Líbano se titula Ahmad $a l-Z a^{c} t a r$, sobre la resistencia del campamento de refugiados palestinos de Tall al- $\mathrm{Za}^{c}$ tar frente a los cristianos libaneses y el héroe del poema es "Ahmad el Árabe”. El solo nombre del héroe es ya todo un canto de nacional-confesionalismo (subliminal o no), pues el nombre de Ahmad es un nombre inequívocamente musulmán y sus enemigos (qué... ¿casualidad?) son los cristianos libaneses y los judíos israelíes. Si se acepta la idea del nacionalismo árabe secular de que es árabe quien habla árabe, los enemigos kat đ̃ ibiyyīn y muchos judíos israelíes también serían árabes. El héroe podría haber tenido un nombre árabe aconfesional (Samīr, Gassān, Baššār"); también podría haber sido una mujer. Pero no, el héroe es masculino y musulmán. No hace falta decir que esa ha sido una de las claves de su éxito. Hubiese sido una buena cosa en pro de un nacionalismo árabe verdaderamente laico que el poeta árabe palestino hubiese escrito algún poema antisionista exaltando la arabidad de los judíos de los países árabes contra las pretensiones sionistas y contra el nacional-islamismo y las paranoias antijudías de sus connacionales. Un poeta realmente progresista y revolucionario, partidario de la causa panarabista y de una Palestina verdaderamente democrática y laica en el marco de una Nación Árabe también democrática y laica tendría que haber escrito poemas contra los pogromes antijudíos y en pro de la emancipación de la mujer árabe (en todos los aspectos). Pero todos estos temas brillan por su ausencia en la obra de Darwī̌s, que se ha convertido en el poeta por excelencia de los palestinos y los árabes precisamente (aparte, claro está, de su innegable talento poético) por no tocar jamás los temas vidriosos y no hacer jamás ninguna crítica interna.

Los judíos eran posiblemente la comunidad más culta y avanzada de Iraq en los años cuarenta. Además eran la comunidad judía arabófona más arabizada pues no sólo tenían como lengua coloquial un dialecto árabe sino que el árabe estándar era su principal lengua de cultura. Muchos de ellos, sobre todo los jovenes, no tenían ningún especial interés ni por el judaísmo como tal ni por el sionismo. Es muy posible que esta comunidad, de haberse encontrado en un medio más favorable hubiese continuado en Iraq como vanguardia cultural y nacional. Por muchos motivos la contribución de los judíos iraquíes podría haber sido muy valiosa para Iraq y el mundo árabe. Pero el confesionalismo islámico y el nacional-islamismo les cerraron ese camino y no les dejaron más salida que la expatriación. El escritor iraquí (afincado en Canadá desde principios de los años cincuenta) judío $\mathrm{Na}^{`}{ }^{1 ̄ m}$ Kattān, en su obra autobiográfica Adiós, Babilonia, dice que aunque todos eran iraquíes y arabófonos (con la excepción de los kurdos, los asirios y algunos otros) los musulmanes se consideraban más iraquíes que los demás y se creían que el país era más suyo que de los demás ${ }^{16}$. Incluso en Israel muchos de estos iraquíes

${ }^{16}$ Naïm Kattan, Adieu Babylone, París, 1975. 
siguieron escribiendo en árabe. La lista de escritores iraquíes que siguieron escribiendo en árabe tras su emigración a Israel es extensa: Šalom Darwī̌s, Sālim Ša ${ }^{c}{ }^{c} \bar{u}^{c}$, Abraham Obadya, Mijā'īl Murād, Šmuel Moreh, Sasson Somej, David Ẓemah, Sālim al-Kātib, Ibrāhīm Mūsà Ibrāhīm, G. Baršan. Es un dato digno de interés que la primera novela árabe que se publicó en Israel no fue obra de un palestino sino del iraquí Ibrāhīm Mūsà Ibrāhīm ${ }^{17}$. Algunos de los que han escrito en hebreo son militantes del partido Rakah, partido comunista no sionista de mayoría palestina; para estos iraquíes, la adaptación a Israel fue muy problemática porque a las dificultades habituales se añadió el hecho de que eran personas cultas y muy politizadas que no se prestaban a representar el papel de "oriental exótico"; los dos escritores iraquíes en lengua hebrea más importantes son Shimón Balas y Sami Mijael (autor de Šawìm we-šawim yoter, "Iguales y más iguales que otros", título que lo dice todo sobre su contenido) ${ }^{18}$.

Los sionistas y luego la mayoría de los israelíes para muchos judíos ortodoxos eran simplemente "gentiles que hablan hebreo", pero un hebreo ("ivrit) que ya no es la "lengua santa" (lašon ha-qodeš) y que por consiguiente no tiene ningún interés para ellos ${ }^{19}$. Los propios sionistas secularistas (la mayoría) tenían como consigna "el último judío, el primer hebreo"20 y veían su proyecto nacional como una manera de liberarse del judaísmo, pues, aunque no cabe duda de que el sionismo tenía un componente mesiánico, se trataba de un mesianismo secularista y modernista. Por ello, para muchos judíos religiosos el sionismo era una herejía y el hebreo moderno una blasfemia.

En esas condiciones es un tanto extraño que lo que para los judíos religiosos era una ideología impía y atea, los integristas islámicos lo admiren a regañadientes en la creencia de que Israel es un estado teocrático judío y el sionismo es un movimiento religioso judío que pese a su perversidad infiel debería servir de modelo y ejemplo a los árabes musulmanes ${ }^{21}$ en su retorno a la religión y a la teocracia. Realmente extraño porque en buena lógica el equivalente árabe más parecido al sionismo sería en todo caso el sector más radicalmente secularista del $\mathrm{Ba}^{\mathrm{c}}$ tismo. Éste podría haber aprovechado el éxito del movimiento sionista para presentarse como su émulo árabe. Por el contrario la propaganda oficial del nacionalismo árabe secularizante insistía en que Israel era un estado teocrático y el sionismo un movimiento "religioso". Este tipo de propaganda, tan torpe como corta de miras (y que de hecho hacía el juego al nacional-sunnismo), insistía hasta la saciedad en paranoias conspiratorias para explicar la guerra del Líbano, como la teoría favorita de la OLP, que culpaba del conflicto del Líbano a una supuesta conspiración sionista para eliminar el modelo de convivencia multiconfesional libanés que sería supuestamente peligroso para Israel. Esta teoría era

17 Gassān Kanafānī, Adab al-muqāwama fī-Filisțīn al-muhtalla, Beirut, 1982, 28.

${ }^{18}$ María Encarnación Varela, Historia de la literatura hebrea contemporánea, Barcelona, 1992, 285-286.

${ }^{19}$ Isaac Bashevis Singer, El penitente, Esplugues de Llobregat (Barcelona), 1984, 119.

${ }^{20}$ Gassān Kanafānī, Fīl-adab al-ṣahyūñ̄, Beirut, 1982.

${ }^{21}$ Emmanuel Sivan, El islam radical. Teología medieval, política moderna, Barcelona, 1997, 64. 
especialmente hipócrita si se tiene en cuenta que la propia OLP cuando le convenía era la primera en insistir en que el Líbano no era un modelo de convivencia pluriconfesional sino un podrido sistema confesionalista que había que aniquilar y que en eso estaban ella y sus aliados en la guerra civil libanesa. La organización principal y mayoritaria dentro de la OLP ha sido el Fath, cuyo nombre significa conquista islámica (las conquistas musulmanas eran las futuhăât, plural de fath) en el sentido de "abrir" por medio del ŷihād un país para el islam. El responsable militar de la organización (hasta su asesinato en abril de 1988 a manos del Mosad) tenía como nombre de guerra Abū Ŷihād. El Fatḥ se formó tomando como modelo al FLN de Argelia. Aun así, sería injusto equiparar totalmente el confesionalismo del Fath al del FLN argelino, pues, pese a todo, aunque sólo fuera por la relativa importancia de la minoría cristiana, el Fath no ha llegado abiertamente a los extremos nacional-islamistas de Argelia. Al fin y al cabo los combatientes de la OLP, fueran del Fath o de otras organizaciones, se

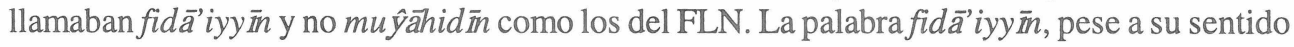
casi místico de entrega por la causa, no tiene el sentido marcadamente confesional de muŷăhidīn, lo que explica que la hayan utilizado también los palestinos no musulmanes. La palabra fedayín ya se había utilizado en su momento para referirse a los guerrilleros armenios cristianos alzados en armas contra los musulmanes turcos y $\operatorname{kurdos}^{22}$. En cualquier caso no era ajeno al carácter sunní del Fath que sus relaciones fueran pésimas no sólo con los cristianos libaneses sino también con los chiíes y con el régimen sirio, mientras que sus relaciones con los elementos sunníes libaneses, incluyendo a los más fanáticos (como la Harakāt al-Tawhīd al-Islāmī del jeque Ša ${ }^{c} b a ̄ n$ ) eran excelentes, lo que sería inaudito si se tomase en serio la propaganda del Fath. En realidad los eslóganes democrático-laicistas del sector musulmán mayoritario en la OLP eran simple propaganda de cara a la progresía occidental.

La única organización de la OLP con un programa cuya idea de tawra tuviera algo que ver con lo que fuera del mundo árabe se entendía por "revolución" era el Frente Democrático para la Liberación de Palestina, cuyo dirigente, Nāyef Hawatme, católico bizantino de origen, no gozaba de muy buena fama entre la gente del Fath (en su mayoría musulmana). En 1970 en Jordania el FDLP proclamó en Irbid el primer soviet árabe y sus militantes llegaron a utilizar los alminares de las mezquitas para difundir su propaganda marxista. Mientras que las relaciones del Fath con el régimen sirio eran pésimas, las del FDLP y el FPLP (también dirigido por un cristiano, en este caso el ortodoxo George Habaš) eran bastante mejores. Mientras que el Fath nadaba en la abundancia gracias a las generosas contribuciones de los pretrodólares de las monarquías de Arabia, el presupuesto del FPLP y todavía más el del FDLP eran muchísimo más modestos. El Fath hablaba de tawra (su lema era precisamente al-tawra hattà al-nașr, "revolución hasta la victoria") pero su țawra iba dirigida exclusivamente contra Israel y en su momento contra los cristianos libaneses, sin cuestionar jamás ningún régimen árabe por reaccionario que fuese (de hecho las petromonarquías eran las que sostenían económicamente al Fatḥ). La tawra palestina del Fath no podía ser más inocua para los intereses de los plutócratas del petróleo y el orden constituido.

\footnotetext{
22 Yves Ternon, Les arméniens. Histoire d’un génocide, París, 1977, 136-141.
} 
Por muchos motivos, Siria era el país árabe donde la pasión nacionalista (que incluía la pasión por la lengua árabe) se aunaba con las tendencias laicistas más audaces. Uno de los principales ideólogos del ba ${ }^{c}$ tismo, Zakī al-Arsūzī, era de origen ' ${ }^{c}$ alawí y originario del liwa de Iskandarún, hombre partidario de un purismo lingüístico extremo y con teorías estrambóticas y místicas sobre la lengua, era a la vez un acérrimo laicista y un rendido admirador de la "autenticidad" ( $a s ̣$ ăla) árabe pero no la identificaba con el islam sino con el periodo preislámico conocido como la Yahiliyya. Su pertenencia a una minoría extremadamente marginal y oprimida por los sunníes y su condición de refugiado procedente del liwa $\vec{a}$ ocupado por los turcos, hacían que su simpatía por el nacional-sunnismo fuera nula.

Pero incluso en Siria, el país árabe más propicio a un arabismo laico, las tendencias secularistas más radicales del $\mathrm{Ba}^{c} t$ encontraron una oposición extrema. El artículo ateo publicado en la revista militar $\hat{Y}$ ayš al-Sac $b$ el 25 de abril de 1967 que calificaba al islam de "momia en el museo de la historia" y llamaba a la creación del "nuevo hombre árabe socialista" despertó muchas más iras y un escándalo mucho mayor que la bochornosa derrota ante Israel con la consiguiente pérdida del Golán y la cruel expulsión de la mayor parte de sus habitantes por los invasores israelíes apenas un mes y pico después. El autor y el editor del "artículo ateo" fueron condenados a cadena perpetua en Siria ante la presión de las manifestaciones y tumultos. Sin embargo los principales pensadores árabes abiertamente teóricos del laicismo han sido sirios, como Ŷalāl Șādiq al-'Azm y Bū ${ }^{\mathrm{c} A l i ̄ ~ Y a ̄ s i ̄ n . ~}$ Recientemente un escritor sirio, Haydar Haydar, ha sido noticia cuando a principios de mayo del 2000, miles de estudiantes egipcios se manifestaron contra el ministro de cultura, Fārūq Husnī, y se enfrentaron a la policía en protesta por la reimpresión de la novela considerada blasfema El banquete de las algas, de Haydar Haydar; la movilización causó docenas de heridos y un centenar de detenidos. Respondía a la campaña del periódico $a l-\breve{S} a^{c} b$ que llegó a pedir la eliminación física de los editores del libro ${ }^{23}$.

Lo que estos fanáticos parecen ser incapaces de entender es que el éxito de un idioma es que sea capaz de expresar religiones, ideologías y opiniones variadas y antagónicas. El árabe fue un gran idioma cuando lo usaban como medio de expresión musulmanes, paganos, cristianos, judíos, sabeos, maniqueos e incrédulos, árabes $y^{c}$ ayam, proárabes y antiárabes. Los šucubíes mismos enriquecían la lengua y la cultura árabes que decían aborrecer. El triunfo de un idioma es que sus mismos enemigos lo empleen aunque sea a su pesar y sin sentir por él ningún aprecio. Esto lo ha entendido muy bien "el enemigo sionista", cuando, por boca de uno de sus más preclaros escritores, el novelista Amós Oz, celebraba que el novelista árabe Antón Šammās escribiese su obra en hebreo aunque fuese para atacar y vituperar al Estado de Israel ("si un escritor israelí no judío escribe una obra importante en hebreo, eso significa que lo hemos conseguido"). A lo que Amós $\mathrm{Oz}$, un intelectual sionista laico se refiere, es a que eso significa la normalización completa de la lengua hebrea, que no sólo haya pasado de ser la 
"lengua santa" del judaísmo a ser la lengua nacional viva de una nación hebrea secular, sino que tenga capacidad de atracción suficiente para que la utilicen incluso los israelíes no judíos.

En ese aspecto la lengua árabe ha sido incapaz de seducir a los no musulmanes y la actitud de los musulmanes hacia el idioma ha llevado a muchos no musulmanes a repudiarlo. A esto se añade la cuestión de la diglosia, que hace que el idioma materno, que provoca en sus hablantes una lealtad espontánea, en el caso de los arabófonos esté lejos de la lengua estándar, por lo que el apego a esta forma estándar exige un compromiso idelógico confesional (en el caso islámico), nacionalista (en el caso de los partidarios del panarabismo) o cultural. Que la lengua estándar provocase en los árabes una lealtad espontánea extraideológica exigiría que la fuṣhà sustituyese a la ${ }^{c} \bar{a} m m i y y a$ como lengua hablada de uso corriente y que las nuevas generaciones árabes la hablasen como lengua materna de un modo parecido a como las nuevas generaciones israelíes hablan el hebreo. Pero eso implicaría una revolución cultural muy poco probable. Los que resucitaron el hebreo eran judíos nacionalistas que aunaban el nacionalismo hebreo con el rechazo de la tradición judía, su idea de resucitar el hebreo se inscribía en la idea de un cambio radical. Nada de eso se ve hoy por hoy en el mundo árabe.

En el caso sionista, la revolución nacionalista había hecho suya la causa del hebreo rechazando el yidish que se veía como lengua de la tradición de la que se quería escapar y rechazando a la vez el adoptar el alemán (o el francés o el inglés), lo que hubiera sido una opción asimilacionista. Es significativo que los sionistas rechazaran el yidish ("judío") de Europa oriental y fuesen partidarios del hebreo. El propio nombre de ambos idiomas ya lo decía todo: se trataba de dejar algo específicamente judío (y confesional) por lo hebreo. Además los sionistas que revitalizaron el hebreo como lengua viva, aunque eran askenazim, no utilizaron la pronunciación ashkenazi (que para ellos era la pronunciación de la sinagoga) sino que optaron por la pronunciación sefardí que les parecía más geunuina y que para ellos, ashkenazim, no tenía sentido religioso sino que les retrotraía a los tiempos bíblicos, en otras palabras: adoptaron la pronunciación sefardí porque les parecía hebrea y no judía.

Las reacciones ante el yidish también dependían de la ideología del opinante. Herman Wook, judío creyente y ortodoxo, describe así el yidish en términos sumamente positivos:

"Creo muy improbable al la resurrección del yiddish entre los judíos de los Estados Unidos. El renacimiento actual de la cultura judía se centra en el hebreo moderno. La gradual extinción de la Prensa y el teatro yiddish en Norteamérica, que antes conocieron gran auge, es trágico, pero es un hecho producido por causas fácilmente comprensibles. Yo considero un privilegio que transcurriera mi niñez cuando esta cultura aún estaba en plena lozanía, lo que me permitió adquirir el conocimiento del yiddish con un mínimo esfuerzo.

El yiddish es un dialecto extraordinariamente expresivo y fulgurante basado en el Alto Alemán, repleto de palabras tomadas de otros idiomas e impregnado con las máximas, idiotismos y frases hechas de la erudición hebrea. Estas numerosas aportaciones prestan a dicha lengua una vivacidad notable. Quienes lo hablan producen la impresión de ser todos poetas o filósofos. Se escribe y se imprime en caracteres hebreos. En Israel, más de la mitad 
de la población anciana conoce el yiddish. Este sigue siendo el lenguaje corriente para el pequeño grupo de ortodoxos esparcidos por el mundo.

Es una equivocación predecir la extinción del yiddish para un futuro inmediato. Un genio universal de la literatura, Sholem Aleichem, posee una obra escrita en esta lengua, y en el siglo XIX floreció un pléyade de autores que apenas podría considerárseles inferiores. Cuando existe semejante literatura, es difícil que la lengua en que se ha escrito desaparezca. Más importante aún " para aquellos que prefieren razonar en términos económicos - es el hecho de que el yiddish es la lengua franca de las considerables y florecientes comunidades judías de la América del Sur y Central. En estos países, el estudio del yiddish y la Prensa publicada en esta lengua conservan su plena lozanía"24.

En cambio un judío secular, partidario, bien del sionismo, bien de la asimilación, como era el caso de Arthur Koestler, no encontraba nada positivo, nada de atractivo y nada de admirable en el yidish, "la lengua del gueto", a la que despreciaba tanto como aborrecía al gueto mismo. Su opinión sobre el yiddish no podía ser más negativa:

"El judaísmo no me atraía. Me había criado en un ambiente de asimilación, sin raíces en la tradición judía. Mi intelecto se había nutrido de literatura húngara, rusa, francesa e inglesa; la única literatura judía que yo conocía era el Antiguo Testamento, y eso no constituye lo que comúnmente se llama una literatura. Ahora, gracias al movimiento sionista, me encontraba por primera vez en contacto con judíos rusos y polacos que se habían criado en escuelas talmúdicas y hablaban yidisch, un dialecto compuesto de alemán medieval y hebreo, con agregados de ruso, polaco, lituano y letón, según en que región se lo habla. Este dialecto, con su tonada insinuante y rítmica, que convertía toda afirmación en concreta en una afirmación sentimental, me repelía. No poseía una gramática fija, ni sintaxis, ni un vocabulario definido, ni precisión lógica. No se lo hablaba, se lo cantaba, con acompañamiento de ademanes. Nada dicho en yidisch parecía ser una afirmación neta, ni tener un valor definido; todo estaba cargado de matices e insinuaciones, lubricado de sentimiento, envuelto en una especie de penumbra lógica. Este idioma me desagradó, y también la mentalidad que reflejaba, desde la primera vez que lo oí, y nunca perdí mi repulsión hacia él.

Leí algunos cuentos sobre la vida en el ghetto escritos en yidisch, y me sentí más alejado aún. Exhalaban un aire rancio, saturado de olores de callejuelas angostas, de ropa de cama sin ventilar, de estrechez mental y maneras de ser tortuosas; aparecía salpicado de toques de humorismo rancio, basado en el desprecio de sí mismo. En esta literatura había una mezcla de servilismo y arrogancia espiritual, de astucia y de sentimentalismo, de misticismo y codicia, que me producían una sensación de claustrofobia, un deseo de romper una ventana y dejar entrar aire fresco"25.

\footnotetext{
${ }^{24}$ Herman Wook, Este es mi Dios, Barcelona, 1963, 328-329.

${ }^{25}$ Arthur Koestler, Autobiografía. 1. Flecha en el azul, Madrid, 1973, 147-148.
} 
Los sionistas establecidos en Palestina se avergonzaban del yidish, este sentimiento lo expresa muy bien el novelista israelí Hayyim Hazaz por boca de uno de sus personajes: "Bien se sabe que el Yisūv se avergüenza de hablar en yidiš, como si hubiera en ello una afrenta o fuera un pecado. Y lo digo intencionadamente: Se avergüenza. No odia, ni teme, ni reniega, sino que se avergüenza. Mientras tanto habla en hebreo con acento sefardí, que le es lejano y extraño, y lo hace con la cabeza alta, con dignidad, con un conocido orgullo a pesar de que con él no tiene la misma flexibilidad ni la comodidad que con el yidiš, a pesar de que no tiene ni el encanto, ni la espontaneidad ni la saludable vitalidad de una lengua popular"26.

Los idiomas que hablaban los judíos no ashskenazim, salvo los asimilados de Europa occidental y Norteamérica, también tenían un nombre confesional judío.

Los judíos del Kurdistán, que hablaban un dialecto neoarameo oriental similar al de los cristianos llamados asirios, llamaban a su idioma "lengua del targum", lïsna yehudiyya (lengua judía) o lason ha-galut (idioma de la diáspora) y a sí mismos anše targum ("gente del targum" en el sentido de "gente del idioma del targum") ${ }^{27}$. Claras referencias al papel de su lengua aramea en la religión judía. Los árabes en cambio lo llamaban ŷabalī, o sea, lengua de los montañeses. Los cristianos nestorianos que tienen un habla muy similar al de estos judíos, llaman a su idioma "asirio" desde que los misioneros británicos anglicanos del siglo XIX vieron en ellos al remanente de los asirios de la antigüedad y los propios nestorianos aceptaron con orgullo este origen y lo reivindicaron.

Al español hablado por los sefardíes, a pesar de no ser muy diferente del que hablan el resto de los hispanohablantes, sus usuarios lo han llamado "yudío" (de un similar a como los judíos ashkenazim llaman yidish a su idioma) mientras que en España, en un medio mayoritariamente católico, a hablar en español le llamaban "hablar en cristiano". Rodeados como estaban de extraños en lo lingüístico, lo confesional y lo étnico, para los sefardíes de los países árabes, Turquía o los Balcanes, hispanohablante y judío eran términos casi sinónimos; para ellos quizás no todos los judíos fueran hispanohablantes (por ejemplo en el Magreb se distinguía entre tošavim, "residentes", o sea, indígenas hablantes de árabe o bereber y megorašim, "inmigrantes" que eran los sefardíes; en Grecia al lado de la mayoría sefardí había una minoría de judíos griegos o romaniotas) pero todos los hispanohablantes que conocían eran judíos.

Una divergencia confesional puede acabar provocando una divergencia lingüística. Ese es el caso del hindustaní que ha dado lugar a dos idiomas: el urdu de los musulmanes (aunque no han faltado hindúes que han escrito en urdu) y el hindi de los hindúes. En lo básico el hindi y el urdu son el mismo idioma, sólo que el urdu se escribe con el alfabeto árabe y está repleto de vocabulario árabe-persa mientras que el hindi se escribe en alfabeto devanagari y sustituye el vocabulario árabe-persa por sanscritismos. El urdu se ha convertido en el idioma oficial de

\footnotetext{
${ }^{26}$ Arthur Koestler, Autobiografía. 1. Flecha en el azul, Madrid, 1973, 147-148.

27 Abraham Ben-Yaacob, s.v "Kurdistan", Encyclopedia Judaica, volumen 10, Jerusalén, 1972, 1302.
} 
Pakistán y en la India se ha tratado de dar al hindi un rango similar pero no ha sido posible a causa de la oposición de los hablantes de otras lenguas, sobre todos en el sur, donde prefieren que el inglés siga siendo la lengua panindia a que se les imponga como lengua nacional el hindi del norte. Como el habla corriente de los hablantes normales estaba saturado de léxico árabe-persa, los pruritos sanscritizantes del hindi provocaron que para los campesinos hindúes de la India la radio de su país les fuera ininteligible y prefiriesen oír la radio pakistaní en urdu. Esto dice mucho acerca de lo artificial de la actitud india. Pero la aversión al vocabulario árabe-persa y el afán de eliminarlo y sustituirlo por neologismos sanscritizantes (incluso de los vocablos más corientes y cotidianos) era una manifestación del deseo de muchos hindúes de borrar todo rastro de los musulmanes y su cultura en la India. En cualquier caso, con el tiempo, en la zona hindihablante del norte (el llamado hindi-belt) el hindi ha ido consiguiendo un moderado avance a costa del urdu entre los mismos musulmanes y, ya a finales de los años setenta, en las encuestas lingüísticas más de un veinte por ciento de los musulmanes reconocían tener como idioma el hindi y no el urdu ${ }^{28}$. En el Decán, donde el hindi no tiene relevancia alguna, los musulmanes se aferran al urdu como lengua comunitaria y se ha llegado a dar el caso de que conversos hindúes al islam hayan tendido a sustituir su idioma drávida por el urdu, por considerarlo el idioma de los musulmanes que ellos también deben hablar mientras que su idioma tradicional sería "el idioma de los idólatras".

El bengalí es compartido por hindúes y musulmanes y unos y otros lo escriben con el mismo alfabeto de tipo indio escrito de izquierda a derecha como todos los alfabetos indios. A pesar de que el bengalí hablado por los musulmanes tenga un vocabulario de origen árabepersa más extenso, el idioma bengalí se ha sentido como mucho más secular y supraconfesional que el urdu. El bengalí es un idioma que une a musulmanes e hindúes, que pueden estar muy enfrentados entre sí, pero que están orgullosos de su cultura e idioma bengalíes frente a las pretensiones del hindi o del urdu. Mientras que el urdu se ha configurado como la lengua de los musulmanes frente a los hindúes y sus idiomas de "idólatras", el bengalí se ha afirmado como lengua de los bengalíes hindúes y musulmanes frente a las pretensiones de sus respectivos correligionarios de imponerles los idiomas hindi o urdu y, en Bangladesh, específica y violentamente contra la hegemonía del urdu que trataba de imponer el Pakistán Occidental cuando Bangladesh era todavía Pakistán Oriental. Esta imposición y la colonización que los bengalíes sufrían a manos de los pakistaníes occidentales, todo ello en nombre del islam, fue lo que llevó a la independencia de Bangladesh. Si el Pakistán se creó en nombre de la islamidad (aunque para los sectores más laicos del pakistanismo ésta fuera sólo cultural y en nombre de la especificidad nacional de los musulmanes de la India, no teocrática), Bangladesh se separó del Pakistán en nombre de su identidad bengalí a despecho del islam que lo unía a Pakistán. Mientras que Pakistán significa "país de los puros", Bangladesh significa "patria bengalî".

${ }^{28}$ Roland Breton, Geografía de las lenguas, Vilassar de Mar (Barcelona), 1979, 52. 
Este caracter laico de la bengalidad y del propio idioma bengalí explica, a mi entender, la diferente reacción hacia sus respectivas nacionalidad y lengua de la egipcia Șafā' Fatḥ̄ y de la bengalí Taslima Nasrin. Esta última se siente orgullosa de su idioma bengalí y de su identidad bengalí. El diferente tratamiento de la cuestión del nacional-islamismo explica, asimismo, el éxito de Mahmūd Darwīš frente al escándalo de la escritora bengalí. Mientras que uno escribía sobre el tema "políticamente correcto" de la manera más "políticamente correcta" y recibía por ello los parabienes de todo el mundo árabe, la otra cogía al toro por los cuernos y cuestionaba abierta y radicalmente el nacional-islamismo y defendía abiertamente a la minoría hindú víctima de los pogromes musulmanes, abogaba incondicionalmente por la laicidad de Bangladesh, repudiaba la "solidaridad islámica" como chovinismo confesional, se declaraba abiertamente atea y opuesta de toda religión ("La religión es la semilla, el árbol es el fundamentalismo. Puedes cortar el árbol. Pero la semilla sigue, y el árbol volverá a crecer. Mientras no quites la semilla, no acabarás con los fundamentalistas") y en sus poemas eróticos denunciaba las relaciones desiguales entre los sexos volviendo la oración por pasiva del modo más provocativo y sin pelos en la lengua ${ }^{29}$.

Uno de los faros de la moderna literatura bengalí es un poeta cristiano, Madhusudam-Dutt, y es significativo que el Ramayana haya sido la fuente de inspiración de su poema más importante. En el caso de los cristianos la relación con la cultura hindú no es tan conflictiva, muchos cristianos de la India se sienten orgullosos de su tradición hindú de un modo parecido a como fervorosos cristianos de Europa pueden sentirse orgullosos de la cultura grecorromana precristiana. Muchos cristianos indios no tienen inconveniente en llevar nombres de dioses hindúes similares a los que llevan los hindúes y esto ocurre incluso en Goa; recuerdo a una cristiana de Goa que se llamaba Usha Albuquerque, o sea, tenía un apellido portugués y su nombre propio era el de la diosa védica de la aurora. Esto no nos puede sorprender mucho a los europeos cuando en el mundo cristiano occidental ha habido hasta santos que se han llamado Isidoro, un nombre que es un teóforo isíaco, o, en la actualidad, Diana, nombre de una diosa romana, es un nombre corriente. Entre los cristianos del Creciente Fértil y Egipto tampoco son infrecuentes los nombres antiguos que rinden tributo a las figuras ilustres de la antigüedad patria; así hay coptos que se llaman Ramsés y entre los asirios son muy corrientes los nombres de Sargón o Shamiram (Semíramis). De esta tendencia han participado hasta los israelíes, que se han dedicado a recuperar nombres de personajes de la Biblia, incluyendo, para escándalo de los judíos piadosos, los de aquellos que se consideraban réprobos por el judaísmo: muchos padres han llegado a dar a sus hijos nombres como Nemrod (que según el Talmud fue uno de los cinco hombres más malvados que han existido) ${ }^{30}$; en todo caso se trataba de una manifestación antroponímica de la tendencia del sionismo laico a exaltar y recuperar lo que hay de hebreo y de semítico en la Biblia en detrimento de lo judío. Este fenómeno de resucitar los nombres antiguos también se dio desde principios del siglo XIX

${ }^{29}$ El País, sábado 18 de junio de 1994, 27.

${ }^{30}$ Paul Johnson, La historia de los judíos, Buenos Aires, 1991, 543-544. 
entre los griegos, cuando, con gran escándalo de las autoridades eclesiásticas, los padres empezaron a bautizar a sus hijos con nombres como Aristóteles, Aspasia, Arístides o Temístocles de los antiguos helenos en lugar de los nombres del santoral ortodoxo. 
